\title{
Short Communication: Lack of Effect of Maraviroc Intensification on Blood and Gut Reservoir
}

\author{
Juan Tiraboschi,, Shuvra Ray,, Kemal Patel, ${ }^{1}$ Matt Pace, ${ }^{2}$ Prabhjeet Phalora, ${ }^{2}$ Nicola Robinson, \\ Emily Hopkins, Jodi Meyerowitz,, Yanzhong Wang, Olubanke Davies, 'Christine Mant, \\ John Cason, Steve Kaye, Jeremy Sanderson, Sarah Fidler, Paul Klenerman, \\ John Frater, ${ }^{2,5,6}$ and Julie Fox ${ }^{1}$
}

\section{Abstract}

We show that intensification of treatment with maraviroc in patients chronically infected with HIV-1 receiving successful long-term antiretroviral therapy was not associated with improvements in HIV-related morbidity, HIV reservoir, microbial translocation, immune activation, or immune exhaustion in either gut or peripheral blood. The measurement of reservoir in both gut and blood longitudinally contributes to a paucity of data in the area.

Keywords: HIV, immune activation, microbial translocation, viral reservoirs, antiretroviral therapy

\section{Background}

D ESPITE THE HUGE SUCCESS of antiretroviral therapy (ART), increased morbidity compared with HIVuninfected individuals continues, ${ }^{1}$ particularly in those with a blunted CD4 response to ART. ${ }^{2}$ A cure for HIV remains elusive and this is, in part, because of an inaccessible longlived pool of latently infected cells, the viral reservoir, which is focused in the gut-associated lymphoid tissue. ${ }^{3}$

Intensification of ART in individuals with suppressed plasma viremia has not consistently reduced viral reservoir or improved immune function. ${ }^{4,5}$ The $\mathrm{C}-\mathrm{C}$ chemokine receptor type 5 (CCR5) entry inhibitor, maraviroc, is an attractive option as CCR5 receptors are most numerous in the gut and the drug penetrates tissue well. ${ }^{6}$ Studies suggest a possible role in increasing CD4 count ${ }^{7,8}$ and reducing immune activation., The gut has been less investigated, ${ }^{4}$ with no consensus on microbial translocation ${ }^{5,10,11}$ or immune activation. ${ }^{10,11}$

We investigated the effect of maraviroc intensification on gut immune function and viral reservoir.

\section{Methods}

\section{Study design and recruitment}

A prospective study whereby 10 individuals with chronic HIV infection with sustained virological suppression on ARV for $>12$ months and a CD4+ T cell count less than 500 cells/ $\mathrm{mm}^{3}$ were intensified with a 24 -week course of standard dose maraviroc. Blood samples were collected at weeks $0,4,12$, and 24. At baseline and week 24, individuals underwent flexible sigmoidoscopy, in which 8-10 rectal biopsies were taken and fixed overnight in $10 \%$ normal buffered formalin at $4^{\circ} \mathrm{C}$.

\section{Laboratory tests}

Bacterial translocation. Plasma bacterial 16s DNA was quantified by real-time polymerase chain reaction (RTPCR). ${ }^{11}$ Plasma sCD14 was quantified using the Quantikine Human sCD14 Immunoassay (R\&D Systems, Minneapolis, $\mathrm{MN}$ ), according to manufacturer's instructions. All samples were run in duplicate.

\section{HIV reservoir and residual viraemia}

Low copy viral load was measured with an internally controlled ultrasensitive quantitative RT-PCR able to detect 3 copies/ml. Purified peripheral blood CD4 T cells were analyzed by quantitative PCR (qPCR) for HIV-1 DNA (total and integrated) and cell-associated HIV-1 RNA unspliced transcripts as reported elsewhere. ${ }^{12}$

For preparation of the gut biopsies for HIV reservoir quantitation, a commercial kit was used (Cat. No. 56404; Qiagen, Hilden, Germany), and the manufacturer's protocol

\footnotetext{
${ }^{1}$ Department of Genitourinary Medicine, Guys and St. Thomas' NHS Foundation Trust, London, United Kingdom.

${ }^{2}$ University of Oxford, Oxford, United Kingdom.

${ }^{3}$ Department of Infectious Diseases, Kings College London, London, United Kingdom.

${ }^{4}$ Imperial College London, London, United Kingdom.

${ }^{5}$ Oxford National Institute of Health, Oxford, United Kingdom.

${ }^{6}$ Oxford National Institute of Health Research Biomedical Research Centre, Oxford, United Kingdom.
} 
modified as follows to ensure maximum yield of DNA. Biopsy sections were removed from paraffin blocks using a scalpel and placed into $1.5 \mathrm{ml}$ micro centrifuge tubes. Samples were washed repeatedly with xylene and ethanol until the precipitate had disappeared, then dried at room temperature. Biopsy sections were incubated at $37^{\circ} \mathrm{C}$ and DNA was extracted using a commercial kit (QIAAMP DNA FFPE Tissue Extraction Kit, ID 56404; Qiagen). The resulting DNA was eluted into $200 \mu \mathrm{l}$ and analyzed by qPCR using the same assays for peripheral blood CD4 cells as already detailed.

\section{Immune activation and lymphocyte subsets}

Peripheral blood mononuclear cells isolation were stained with the anchor markers (CD3- VioBlue, CD4 (VIT4)VioGreen, and CD8-APC) and a live/dead marker near IR APC-Cy7 plus either an activation panel [CD25 (3G10)-PE, CD38-PE-Vio770, CD69-FITC, and anti-HLA-DR-PerCP] or an exhaustion panel (TIGIT-PE, TIM-3-FITC, LAG-3PerCPeF710, and PD1-PE-Cy7). Cells were run on a MACSQuant and analyzed with FlowJo software v10 (Miltenyi Biotec).

\section{Immunohistochemistry}

Rectal biopsy sections were stained for CD4 (goat polyclonal; Novus Biologicals) and CD8 antibodies (rabbit polyclonal; Abcam). Images were analyzed in ImageJ and the distribution of cells was determined as described by Milano et al. ${ }^{13}$

\section{Statistics}

For each outcome measure, the results at baseline and week 24 were compared using the paired $t$-test. Wilcoxon rank test was used to assess the impact of tropism on each parameter.

\section{Results}

\section{Patient characteristics}

The median age was 46 years. All patients were male with subtype B virus and were receiving two nucleoside reverse transcriptase inhibitors (NRTIs) combined with either a nonNRTI $(n=5)$ or protease inhibitor $(n=5)$. The mean CD4 $\mathrm{T}$ cell count was 321 cells/ $\mu \mathrm{l}$ (SD 112), CD4:CD8 0.51 (SD 0.27 ), and nadir CD4 117 cells/ml (SD 135). All patients were maintained an HIV viral load $<50$ copies $/ \mathrm{ml}$ throughout the study. Individual plots of viral reservoir, microbial translocation, and immune activation are shown in Table 1 and mean changes in parameters between week 0 and 24 are shown in Figure 1.

\section{Baseline to week 24}

Clinical outcome/T cell subsets composition in blood and gut. Between baseline and week 24 (Table 2) in the blood, there was a nonsignificant increase of $48.22 \mathrm{CD} 4 \mathrm{~T}$ cells $/ \mathrm{ml}$ $(p=.275)$ and $39.23 \mathrm{CD} 8 \mathrm{~T}$ cells $/ \mathrm{ml}(p=.672)$, whereas CD4:CD8 did not change. This was accompanied by a nonsignificant reduction in gut CD4 $(-0.80 ; p=.087)$ and gut CD8 T cells $(-5.59 ; p=.052)$. Changes in blood CD4 and CD8 lymphocytes did not correlate with changes in these cells in the gut.
Table 1. Individual Values for Key Parameters BetWeEN WeEK 0 AND 24

\begin{tabular}{lcccccc}
\hline Participant & \multicolumn{2}{c}{ CD8CD38 } & \multicolumn{2}{c}{$16 s D N A$} & \multicolumn{2}{c}{ HIVDNA } \\
\hline A & 0 & 24 & 0 & 24 & 0 & 24 \\
B & 2.07 & 65.4 & 9.59 & 24.79 & $2,261.3$ & $1,613.3$ \\
C & 31.4 & 3.77 & 13.73 & 6.84 & $2,961.3$ & $2,330.2$ \\
D & 67.4 & 72.1 & 4.49 & 5.41 & $2,961.4$ & 747.3 \\
E & 40 & 79.4 & 4.89 & 6.51 & $2,877.3$ & $2,826.5$ \\
F & 7.96 & 68.5 & 3.65 & 3.38 & $3,621.1$ & $1,645.3$ \\
G & 28.5 & 6.08 & 6.59 & 2.07 & $4,141.3$ & 4,384 \\
H & 71 & 55.1 & 4.87 & 3.47 & $4,968.3$ & $6,701.6$ \\
I & 78.1 & 3.1 & 7.72 & 7.6 & $8,452.1$ & $12,026.7$ \\
J & 67.7 & 16.7 & 10.61 & 4.21 & $2,129.7$ & 1,968 \\
\hline
\end{tabular}

Bacterial translocation. Between baseline and week 24, there was no significant change in 16s DNA copies $(-0.60$; $p=.797)$ or $\mathrm{sCD} 14 \mathrm{a}(+59.35 ; p=.637)$.

HIV reservoir. Neither HIV RNA, HIV DNA (blood or gut), or cellular HIV RNA changed significantly between baseline and week 24 or between baseline and week 12. At baseline, gut HIV DNA levels (mean 101,806 copies/million cells) were significantly higher than those in blood $(3,669$ copies/million CD4 T cells) ( $p=.017)$.

$\mathrm{T}$ cell activation and exhaustion. The level of activation of $\mathrm{CD}^{+} \mathrm{T}$ cells and $\mathrm{CD} 8^{+} \mathrm{T}$ cells showed nonsignificant increases from baseline to week 24 in six parameters



FIG. 1. Individual change in key parameters between week 0 and 24. 
Table 2. Mean Changes in Parameters Between Week 0 and 24

\begin{tabular}{|c|c|c|c|c|}
\hline Outcome variable & $\begin{array}{c}\text { Mean }(S D) \\
\text { week } O \text { (visit 2) } \\
\mathrm{N}=10\end{array}$ & $\begin{array}{c}\text { Mean }(S D) \\
\text { week } 24 \text { (visit 5) } \\
\mathrm{N}=9\end{array}$ & $\begin{array}{c}\text { Mean } \\
\text { difference } \\
\text { (week 24-0) } \\
\mathrm{N}=9\end{array}$ & $\mathrm{p}$ \\
\hline \multicolumn{5}{|l|}{ Microbial translocation } \\
\hline $\begin{array}{l}\text { 16s DNA copies } / \mu \mathrm{l} \\
\mathrm{scd} 14 \mathrm{ng} / \mathrm{ml}\end{array}$ & $\begin{array}{c}7.95(3.7) \\
1,781.56(355.16)\end{array}$ & $\begin{array}{c}7.69(6.73) \\
1,783.02(438.14)\end{array}$ & $\begin{array}{l}-0.60 \\
59.35\end{array}$ & $\begin{array}{l}.7972 \\
.6368\end{array}$ \\
\hline \multicolumn{5}{|l|}{ Clinical outcome markers } \\
\hline CD4 cells/ml & 334.4 (131.64) & $407.56(154.63)$ & 48.22 & .2751 \\
\hline $\mathrm{CD} 4 \%$ & $24.39(8.77)$ & $24.39(7.02)$ & -1.29 & .3349 \\
\hline CD4:CD8 ratio & $0.51(0.27)$ & $0.54(0.21)$ & 0 & 1 \\
\hline \multicolumn{5}{|l|}{ Reservoir } \\
\hline HIV DNA copies/CD4 T cell & $3,669.41(1,902.92)$ & $3,181.33(3,484.3)$ & -343.76 & .5594 \\
\hline Cell HIV RNA copies/18 s RNA copies & $2,755.62(4,400.75)$ & $991.18(1,130.88)$ & $-1,295.49$ & .5279 \\
\hline Low copy plasma HIV RNA/ml & $16.1(14.96)$ & $38.33(38.12)$ & 21.78 & .1424 \\
\hline \multicolumn{5}{|l|}{ Immune exhaustion } \\
\hline$\%$ CD8 lag3 & $0.91(1.08)$ & $0.44(0.22)$ & -0.52 & .2669 \\
\hline$\%$ CD8pd1 & $0.27(0.23)$ & $0.55(0.41)$ & 0.27 & .1762 \\
\hline$\%$ CD8 tigit & $47.23(13.79)$ & $52.08(16.23)$ & 6.07 & .0059 \\
\hline$\%$ CD8 tim 3 & $0.1(0.09)$ & $0.11(0.1)$ & 0 & .9191 \\
\hline$\%$ CD4 lag3 & $0.24(0.21)$ & $0.26(0.2)$ & 0.08 & .3693 \\
\hline$\%$ CD4 pd1 & $1.01(1.08)$ & $1.64(1.24)$ & 0.98 & .0596 \\
\hline$\%$ CD4 tim 3 & $0.32(0.35)$ & $0.26(0.2)$ & -0.01 & .9074 \\
\hline$\%$ CD4 tigit & $26.56(10.01)$ & $25.3(10.36)$ & 1.63 & .5215 \\
\hline \multicolumn{5}{|l|}{ Immune activation } \\
\hline \% CD4CD25 & $1.73(0.89)$ & $2.19(2.07)$ & 0.58 & .4762 \\
\hline \% CD4CD38 & $0.95(0.52)$ & $1.15(0.94)$ & 0.37 & .2302 \\
\hline$\%$ CD4CD69 & $1.4(1.15)$ & $1.29(0.89)$ & 0.21 & .3268 \\
\hline \% CD4 HLA DR & $4.74(2.5)$ & $5.08(3.01)$ & 1.32 & .163 \\
\hline$\% \mathrm{CD} 8 \mathrm{CD} 38$ & $45.67(27.47)$ & 31.59 (34.97) & -16.37 & .3669 \\
\hline$\%$ CD8CD25 & $2.04(1.3)$ & $1.77(1.77)$ & -0.63 & .3275 \\
\hline$\%$ CD8CD69 & $5.7(4.34)$ & $3.66(1.82)$ & -2.16 & .326 \\
\hline$\%$ CD8 HLA DR & $0.82(0.59)$ & $1.22(0.9)$ & 0.61 & .0482 \\
\hline \% CD8CD38 HLA DR & $0.82(0.59)$ & $1.23(0.84)$ & 0.58 & .0326 \\
\hline \multicolumn{5}{|l|}{ Gut tissue reservoir } \\
\hline HIV DNA copies/million cells & $101,805.93(117,858.81)$ & $51,468.83(109,191.98)$ & $-44,062.84$ & .4738 \\
\hline \multicolumn{5}{|l|}{ Gut cell composition } \\
\hline Total cell number & $93.9(22.33)$ & $93.59(28.52)$ & 1.26 & .9006 \\
\hline CD4 cell number & $22.9(12.52)$ & $16.41(9.98)$ & -8.04 & .0873 \\
\hline CD8 cell number & $11.5(5.79)$ & $6.26(4.57)$ & -5.59 & .0522 \\
\hline Proportion of CD4 cells & $0.25(0.16)$ & $0.18(0.12)$ & -0.09 & .0644 \\
\hline Proportion of CD8n cells & $0.12(0.05)$ & $0.08(0.05)$ & -0.05 & .0898 \\
\hline
\end{tabular}

$\mathrm{SD}$, standard deviation.

(including $\mathrm{CD}^{+} \mathrm{CD} 38^{+} \mathrm{HLADR} ; p=.677$ ) with only percentage CD8 ${ }^{+}$HLADR $(+0.61 ; p=.048)$ increasing significantly. These findings were the same when analyzed from baseline to week 12 with only percentage $\mathrm{CD} 8^{+} \mathrm{HLADR}^{+}$ showing a significant change $(+0.47 ; p=.001)$.

Eight out of 10 immune exhaustion markers increased from baseline to week 24 but only percentage CD8 tigit reached significance $(+6.07 ; p=.006)$. This was supported by analysis of week 0 to 12 [percentage CD8 tigit (mean increase +5.82 ; $p=.004)]$.

\section{Tropism}

Six out of 10 individuals had R5 virus. Tropism (R5 vs. X4 or X4/R5) did not correlate with changes in reservoir, immune activation, immune exhaustion, or microbial translocation (all $p$ values $>.05$ ).

\section{Discussion}

In this pilot study, intensification of treatment with maraviroc in patients chronically infected with HIV-1 receiving successful long-term ART with a blunted CD4 immune response was not associated with any overall improvements in surrogate markers of HIV-related morbidity (CD4 T cell count or CD4:CD8 ratio), microbial translocation, immune activation, or immune exhaustion in either gut or peripheral blood. The isolated significant results in the absence of a broad class-wide effect on $\mathrm{T}$ cell exhaustion or activation are potentially interesting but should not be over interpreted. Furthermore, reservoir did not decline longitudinally in either gut or blood. The large gut HIV reservoir supports interventions targeting this compartment; however, the large intraindividual variation means that sample sizes may need to be large. The lack of impact of tropism on the effect of 
maraviroc on immunological function or reservoir size is novel but limited because of small sample size.

Overall, the study shows no role for maraviroc intensification to improve clinical or immunological outcomes or to provide complete viral inhibition. The null effect may also reflect that these individuals had more resistant immune dysfunction than intensification with ART could repair or the short duration of follow-up. The study is limited by the small sample size and lack of control group but the detailed analysis particularly of the gut further diminishes the investigation of maraviroc as an agent of intensification.

\section{Acknowledgment}

We acknowledge support from the biobank nurse funded by Guys and St. Thomas' NHS Trust and NIHR.

\section{Author Disclosure Statement}

No competing financial interests exist.

\section{References}

1. Volberding PA, Deeks SG: Antiretroviral therapy and management of HIV infection. Lancet 2010;376:49-62.

2. Kaufmann GR, Perrin L, Pantaleo G, Opravil M, Furrer H, Telenti A, Hirschel B, Ledergerber B, Vernazza P, Bernasconi E, Rickenbach M, Egger M, Battegay M: CD4 Tlymphocyte recovery in individuals with advanced HIV-1 infection receiving potent antiretroviral therapy for 4 years: The swiss HIV cohort study. Arch Intern Med 2003;163: 2187-2195.

3. Chun TW, Fauci AS: Latent reservoirs of HIV: Obstacles to the eradication of virus. Proc Natl Acad Sci U S A 1999; 96:10958-10961.

4. Ananworanich J, Chomont N, Fletcher JL, Pinyakorn S, Schuetz A, Sereti I, Rerknimitr R, Dewar R, Kroon E, Vandergeeten C, Trichavaroj R, Chomchey N, Chalermchai T, Michael NL, Kim JH, Phanuphak P, Phanuphak N: Markers of HIV reservoir size and immune activation after treatment in acute HIV infection with and without raltegravir and maraviroc intensification. J Virus Erad 2015;1: 116-122.

5. Gutiérrez C, Díaz L, Vallejo A, et al.: Intensification of antiretroviral therapy with a CCR5 antagonist in patients with chronic HIV-1 infection: Effect on $\mathrm{T}$ cells latently infected. PLoS One 2011;6:e27864.
6. Fox J, Tiraboschi J, Herrera C, Else L, Dickinson L, Back D, Khoo S, Boffitto M: Pharmacokinetic/pharmacodynamic investigation of single dose oral maraviroc in the context of HIV-1 pre exposure prophylaxis (PrEP). J Acquir Immune Defic Syndr 2016;73:252-257.

7. Asmuth DM, Goodrich J, Cooper DA, Haubrich R, Rajicic $\mathrm{N}$, Hirschel B, et al: $\mathrm{CD} 4+\mathrm{T}$-cell restoration after 48 weeks in the maraviroc treatment-experienced trials MOTIVATE 1 and 2. J Acquir Immune Defic Syndr 2010;54: 394-397.

8. Cuzin L, Trabelsi S, Delobel P, et al:: ANRS 145 MARIMUNO Study Group. Maraviroc intensification of stable antiviral therapy in HIV-1-infected patients with poor immune restoration: MARIMUNO-ANRS 145 study. J Acquir Immune Defic Syndr 2012;61:557-564.

9. Funderburg N, Kalinowska M, Eason J, Goodrich J, Heera $\mathrm{J}$, Mayer $\mathrm{H}$, et al.: Effects of maraviroc and efavirenz on markers of immune activation and inflammation and associations with CD4+ cell rises in HIV-infected patients. PLoS One 2010;5:e13188.

10. Hunt PW, Shulman NS, Hayes TL, et al.: The immunologic effects of maraviroc intensification in treated HIV-infected individuals with incomplete CD4+ T-cell recovery: A randomized trial. Blood 2013;121:4635-4646.

11. Jiang W, Lederman MM, Hunt P, Sieg SF, Haley K, Rodriguez B, Landay A, Martin J, Sinclair E, Asher AI, Deeks SG, Douek DC, Brenchley JM: Plasma levels of bacterial DNA correlate with immune activation and the magnitude of immune restoration in persons with antiretroviral-treated HIV infection. J Infect Dis 2009;199:1177-1185.

12. Williams JP, Hurst J, Stohr W: HIV-1 DNA predicts disease progression and post-treatment virological control. eLife 2014;3:e03821.

13. Bologna-Molina R, Damián-Matsumura $\mathrm{P}$, MolinaFrechero N: An easy cell counting method for immunohistochemistry that does not use an image analysis program. Histopathology 2011;59:801-803.

Address correspondence to: Julie Fox, MD

Guys and St. Thomas' NHS Foundation Trust Harrison Wing

2nd Floor Lambeth Wing London SE1 7EH United Kingdom

E-mail: julie.fox@kcl.ac.uk 